\title{
Dynamic vehicle response on horizontal curves equivalent to turnout curves through Swedish UIC60 turnouts
}

\author{
B. Kufver ${ }^{1} \&$ O. Rydell ${ }^{2}$ \\ ${ }^{1}$ Ferroplan, Sweden \\ ${ }^{2}$ Swedish National Rail Administration (Banverket), Sweden
}

\begin{abstract}
In conjunction with an evaluation of vehicle dynamics on horizontal curves where transition curves are not used, the Swedish turnout geometries have been evaluated. The study quantifies the dynamic vehicle response on alignments according to Swedish UIC60 turnouts and compares it with vehicle response on limiting cases according to applicable track standards. Vehicle dynamics is quantified where there are curves in opposite directions, as in crossovers with $4.5 \mathrm{~m}$ track distance. Vehicle dynamics is also illustrated where there are circular curves in the same direction, connected by a short intermediate straight. When a vehicle enters a circular curve, there will be a transient change from the lateral steady-state position on the straight to a new steady-state position on the curve. The simulations show that this transient change in position increases the dynamic lateral wheel/rail forces at the wheel/rail interface compared to the steady-state values on the circular curve. For each curve entry, there is an unfavourable peak load. Such peak loads occur both on circular curves in opposite directions and on circular curves in the same direction that are connected with a short intermediate straight.
\end{abstract}

Keywords: vehicle dynamics, alignment, horizontal curves, turnouts, sidings.

\section{Introduction}

In Japan, Sweden, USA, and China, several studies on alignment optimisation, based on simulations of vehicle dynamics, have been conducted. Various types of transition curves and cant transition ramps (linear or S-shaped) have been 
compared [1-6]. Minimum lengths for straight track elements and circular curves, placed between clothoids and linear cant transitions, have been studied [7]. Optimal combinations of curve radii and clothoids have been evaluated for tilting and non-tilting trains $[8,9]$. These studies were focused on representative main line conditions: High train speeds and horizontal curves that are provided with cant and transition curves. However, certain studies were focused on typical geometries for turnouts and sidings with no transition curves [10-12].

The present study is an extended version of [10,11], focusing on representative radii within the Swedish UIC60 turnouts and curves on sidings. The alignment alternatives consist of combinations of straights and circular curves. The curves are neither canted nor provided with transition curves.

As in earlier Swedish studies, such as [13], the dynamic vehicle response is quantified through computer simulations with the software GENSYS. The same vehicle models (the international standard coach "Eurofima", Figure 1, and the Swedish X2000 tilting train) and track model (UIC60 rails with an inclination of 1:30 according to Swedish practice, lumped flexibility in the vertical direction $150 \mathrm{MN} / \mathrm{m}$, friction coefficient of 0.4 , etc.) are used. In the present study, no track irregularities are superimposed on the nominal track geometry. The evaluation of vehicle motions and wheel/rail forces follows international standards [14-16] as closely as possible.

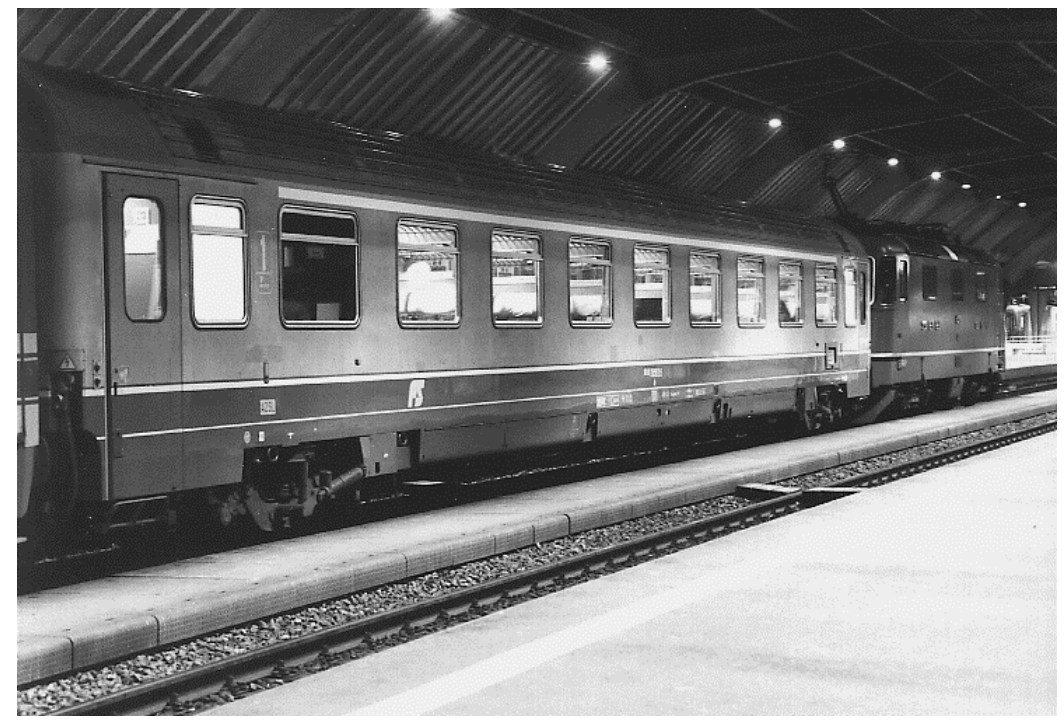

Figure 1: A Eurofima coach at Zürich $\mathrm{Hb}$. This type of coach is used by several railway companies in Europe. Photo: B Kufver.

The alignment cases that have been studied correspond either to various worst cases for sidings, according to the Swedish track standards [17], or to the nominal alignment through the diverging track in Swedish UIC60 turnouts. There are certain discrepancies between the real turnout geometries and the 
geometries in the present investigation: The rails are not inclined, but vertical, on Swedish standard turnouts. Also, the detailed variations of the rail cross sections through the switch zone and the common crossing zone, as well as check rails, are not used in the simulations. Instead, the rail profiles are constant. This approach is adopted because the focus is on the effects of alignment alterations through turnouts (and not on the detailed geometry of switch blades and common crossings), and also on single curves and reverse curves on sidings that do not contain any switches and crossings.

The Swedish track standards [17] permit a cant deficiency of 100-245 mm depending on the characteristics of the vehicle (non-tilting or tilting). If train speed is $100 \mathrm{~km} / \mathrm{h}$ or lower, an abrupt change of cant deficiency of $100 \mathrm{~mm}$ is permitted (on sidings). For train speeds from $105 \mathrm{~km} / \mathrm{h}$ to $160 \mathrm{~km} / \mathrm{h}$, maximum abrupt change of cant deficiency on sidings is $80 \mathrm{~mm}$. The concept of virtual transitions (i.e. lateral jerk is calculated as change of acceleration multiplied by train speed and divided by bogie king pin spacing) is not used in Sweden. However, the reduction of permitted abrupt change of cant deficiency for train speeds above $100 \mathrm{~km} / \mathrm{h}$ is based on similar thoughts: Without this reduction, the lateral jerk is believed to become unacceptably high.

\section{Swedish UIC60 turnouts and crossovers}

Basic types of Swedish UIC60 turnouts are shown in Table 1. The switch has tangential geometry, switch radius and turnout radius are the same and the radius ends at the heel of the turnout.

Table 1: $\quad$ Basic types of Swedish turnouts with UIC60 rails.

\begin{tabular}{|l|l|l|l|l|l|}
\hline Turnout & $1: 9$ & $1: 12$ & $1: 14$ & $1: 18.5$ & $1: 26.5$ \\
\hline Radius $R[\mathrm{~m}]$ & 300 & 500 & 760 & 1200 & 2500 \\
\hline Curve length $[\mathrm{m}]$ & 33.197 & 41.571 & 54.194 & 64.802 & 94.295 \\
\hline $\begin{array}{l}\text { Permissible speed, } \\
\text { diverging track, } V[\mathrm{~km} / \mathrm{h}]\end{array}$ & 50 & 65 & 80 & 100 & 130 \\
\hline
\end{tabular}

There are also two modified turnout versions, where the diverging track consists of a circular curve and a straight. Turnout $1: 15$ is based on turnout $1: 14$, but has a $3.606 \mathrm{~m}$ long straight at the heel. Turnout 1.27.5 is based on turnout $1: 26.5$, but has a $3.427 \mathrm{~m}$ long straight at the heel.

Vehicle response has been simulated for these types of turnout geometries, as used in crossovers between tracks with $4.5 \mathrm{~m}$ track distance (centre to centre), see Tables 2 and 3. Data processing (band-pass filtering, statistical processing) complies with European standards [14, 15].

According to Swedish track standards [17], the use of 1:14 and 1:26.5 turnouts on crossovers between tracks with $4.5 \mathrm{~m}$ track distance is not permitted unless the permissible speed in the crossover is reduced below the permissible speed on a single turnout. The intermediate straight is believed to be too short 
and to generate unfavourable vehicle response. This is the justification for the modified versions 1:15 and 1:27.5 from the basic turnouts. Also, according to the European alignment standards [18], the straight in a 1:14 crossover is too short for a permissible speed of $80 \mathrm{~km} / \mathrm{h}$.

However, Table 3 shows that the vehicle response on 1:14 and 1:26.5 crossovers is better than on other crossovers. There is only one exception. For the $1: 14$ crossover, lateral jerk on entering the second turnout is $1.51 \mathrm{~m} / \mathrm{s}^{3}$, while it is $1.39 \mathrm{~m} / \mathrm{s}^{3}$ for a $1: 18.5$ crossover.

Table 2: Dynamic vehicle response (Eurofima coach) on an alignment according to a single turnout or the first turnout on a crossover.

\begin{tabular}{|l|l|l|l|l|l|l|l|}
\hline Turnout & $1: 9$ & $1: 12$ & $1: 14$ & $1: 15$ & $1: 18.5$ & $1: 26.5$ & $1: 27.5$ \\
\hline Radius $R[\mathrm{~m}]$ & 300 & 500 & 760 & 760 & 1200 & 2500 & 2500 \\
\hline Speed $V[\mathrm{~km} / \mathrm{h}]$ & 50 & 65 & 80 & 80 & 100 & 130 & 130 \\
\hline Max $Q[\mathrm{kN}]$ & 72.5 & 69.6 & 70.2 & 70.2 & 72.3 & 71.1 & 71.1 \\
\hline $\operatorname{Min} Q[\mathrm{kN}]$ & 38.3 & 39.3 & 37.5 & 37.5 & 35.5 & 37.7 & 37.7 \\
\hline $\operatorname{Max} Y[\mathrm{kN}]$ & 33.7 & 27.6 & 21.9 & 21.9 & 17.2 & 9.6 & 9.6 \\
\hline Max $\Sigma Y[\mathrm{kN}]$ & 19.6 & 12.7 & 17.6 & 17.6 & 20.2 & 14.5 & 14.5 \\
\hline Max $Y / Q[-]$ & 0.56 & 0.47 & 0.38 & 0.38 & 0.30 & 0.16 & 0.16 \\
\hline Max acc $\left[\mathrm{m} / \mathrm{s}^{2}\right]$ & 0.91 & 0.89 & 0.92 & 0.92 & 0.96 & 0.82 & 0.82 \\
\hline Max jerk $\left[\mathrm{m} / \mathrm{s}^{3}\right]$ & 0.76 & 0.80 & 0.82 & 0.82 & 0.90 & 0.79 & 0.79 \\
\hline $\begin{array}{l}\text { Max roll } \\
\text { velocity }[\mathrm{rad} / \mathrm{s}]\end{array}$ & 0.015 & 0.016 & 0.015 & 0.015 & 0.018 & 0.018 & 0.018 \\
\hline
\end{tabular}

Table 3: Dynamic vehicle response (Eurofima coach) on an alignment according to the second turnout on a crossover with $4.5 \mathrm{~m}$ track distance. Crossovers 1:14 and 1:26.5 are substandard according to Swedish track standards.

\begin{tabular}{|l|l|l|l|l|l|l|l|}
\hline Turnout & $1: 9$ & $1: 12$ & $1: 14$ & $1: 15$ & $1: 18.5$ & $1: 26.5$ & $1: 27.5$ \\
\hline Radius $R[\mathrm{~m}]$ & 300 & 500 & 760 & 760 & 1200 & 2500 & 2500 \\
\hline Speed $V[\mathrm{~km} / \mathrm{h}]$ & 50 & 65 & 80 & 80 & 100 & 130 & 130 \\
\hline Max $Q[\mathrm{kN}]$ & 73.8 & 69.5 & 71.2 & 71.4 & 74.0 & 71.9 & 69.9 \\
\hline Min $Q[\mathrm{kN}]$ & 37.1 & 41.8 & 36.1 & 37.3 & 34.6 & 37.3 & 39.3 \\
\hline $\operatorname{Max} Y[\mathrm{kN}]$ & 34.5 & 26.2 & 19.8 & 19.8 & 14.9 & 10.9 & 12.4 \\
\hline $\operatorname{Max} \sum Y[\mathrm{kN}]$ & 22.4 & 13.2 & 18.2 & 17.6 & 20.8 & 16.2 & 15.1 \\
\hline Max $Y / Q[-]$ & 0.63 & 0.45 & 0.37 & 0.35 & 0.26 & 0.17 & 0.20 \\
\hline Max acc $\left[\mathrm{m} / \mathrm{s}^{2}\right]$ & 0.97 & 0.90 & 0.95 & 0.90 & 0.94 & 0.81 & 0.76 \\
\hline Max jerk $\left[\mathrm{m} / \mathrm{s}^{3}\right]$ & 1.37 & 1.20 & 1.51 & 1.21 & 1.39 & 1.18 & 0.94 \\
\hline $\begin{array}{l}\text { Max roll } \\
\text { velocity }[\mathrm{rad} / \mathrm{s}]\end{array}$ & 0.029 & 0.021 & 0.028 & 0.023 & 0.030 & 0.028 & 0.022 \\
\hline
\end{tabular}




\section{Worst combinations of curves in opposite directions}

It has also been considered interesting to study the worst cases of curves in opposite directions (according to Swedish track standards [17]), where a track is to be shifted $4.5 \mathrm{~m}$ in the lateral direction. Tables 4 and 5 show vehicle response on curves with $100 \mathrm{~mm}$ cant deficiency and an intermediate straight of $0.10 \cdot V$ [metre per $\mathrm{km} / \mathrm{h}$ ], in certain cases $0.15 \cdot V$. (The analysis of the second curve in the case of $R=189 \mathrm{~m}$ is excluded, since such small radii require a fairly long intermediate straight in order to avoid buffer locking, see [19] for analysis on buffer locking.)

Table 4: Dynamic vehicle response (Eurofima coach) on a single curve or the first circular curve on a curve combination.

\begin{tabular}{|l|l|l|l|l|l|l|l|}
\hline Radius $R[\mathrm{~m}]$ & 189 & 295 & 425 & 579 & 756 & 956 & 1180 \\
\hline Speed $V[\mathrm{~km} / \mathrm{h}]$ & 40 & 50 & 60 & 70 & 80 & 90 & 100 \\
\hline Max $Q[\mathrm{kN}]$ & 74.0 & 72.9 & 70.4 & 69.2 & 70.2 & 71.4 & 72.4 \\
\hline Min $Q[\mathrm{kN}]$ & 37.7 & 37.9 & 39.3 & 39.0 & 37.4 & 36.2 & 36.3 \\
\hline Max $Y[\mathrm{kN}]$ & 42.5 & 34.0 & 29.5 & 25.5 & 21.9 & 19.4 & 17.4 \\
\hline Max $\Sigma Y[\mathrm{kN}]$ & 27.1 & 20.0 & 14.5 & 14.5 & 17.6 & 19.5 & 20.5 \\
\hline Max $Y / Q[-]$ & 0.64 & 0.57 & 0.50 & 0.44 & 0.38 & 0.34 & 0.30 \\
\hline Max acc $\left[\mathrm{m} / \mathrm{s}^{2}\right]$ & 0.86 & 0.93 & 0.89 & 0.90 & 0.92 & 0.95 & 0.98 \\
\hline Max jerk $\left[\mathrm{m} / \mathrm{s}^{3}\right]$ & 0.75 & 0.78 & 0.79 & 0.80 & 0.82 & 0.88 & 0.92 \\
\hline $\begin{array}{l}\text { Max roll } \\
\text { velocity }[\mathrm{rad} / \mathrm{s}]\end{array}$ & 0.016 & 0.016 & 0.016 & 0.015 & 0.015 & 0.017 & 0.019 \\
\hline
\end{tabular}

Table 5: Dynamic vehicle response (Eurofima coach) on the second curve in a direction opposite to the first. The combination $L_{S}=8 \mathrm{~m}$ and $V=80 \mathrm{~km} / \mathrm{h}$ is substandard according to Swedish track standards.

\begin{tabular}{|l|l|l|l|l|l|l|l|}
\hline Radius $R[\mathrm{~m}]$ & 295 & 425 & 579 & 756 & 756 & 956 & 1180 \\
\hline Straight $L_{S}[\mathrm{~m}]$ & 5 & 6 & 7 & 8 & 12 & 13.5 & 15 \\
\hline Speed $V[\mathrm{~km} / \mathrm{h}]$ & 50 & 60 & 70 & 80 & 80 & 90 & 100 \\
\hline Max $Q[\mathrm{kN}]$ & 75.2 & 71.6 & 69.8 & 71.4 & 71.3 & 73.2 & 74.6 \\
\hline $\operatorname{Min} Q[\mathrm{kN}]$ & 36.6 & 38.2 & 38.1 & 35.8 & 36.5 & 34.7 & 38.2 \\
\hline $\operatorname{Max} Y[\mathrm{kN}]$ & 36.8 & 31.2 & 26.2 & 21.5 & 19.0 & 14.5 & 15.0 \\
\hline Max $\Sigma[\mathrm{kN}]$ & 23.8 & 17.5 & 14.8 & 18.7 & 17.7 & 20.2 & 21.9 \\
\hline Max $Y / Q[-]$ & 0.65 & 0.56 & 0.48 & 0.40 & 0.34 & 0.27 & 0.02 \\
\hline Max acc $\left[\mathrm{m} / \mathrm{s}^{2}\right]$ & 1.01 & 0.93 & 0.93 & 0.97 & 0.93 & 0.96 & 0.99 \\
\hline Max jerk $\left[\mathrm{m} / \mathrm{s}^{3}\right]$ & 1.53 & 1.50 & 1.46 & 1.54 & 1.42 & 1.50 & 1.54 \\
\hline $\begin{array}{l}\text { Max roll } \\
\text { velocity }[\mathrm{rad} / \mathrm{s}]\end{array}$ & 0.033 & 0.030 & 0.028 & 0.029 & 0.026 & 0.030 & 0.032 \\
\hline
\end{tabular}

\section{Combinations of curves in the same direction}

There are cases where a turnout is connected with a curve in the same direction. In such cases, a continuous curve is normally preferred, since it requires a shorter 
length and since the vehicle motions will be less transient. However, for turnouts with a straight at the heel, a continuous curve cannot be arranged. Figures 2 and 3 show some relevant cases, comparing the basic 1:14 turnout which has constant radius with the modified 1:15 turnout which also contains a straight in the diverging track.
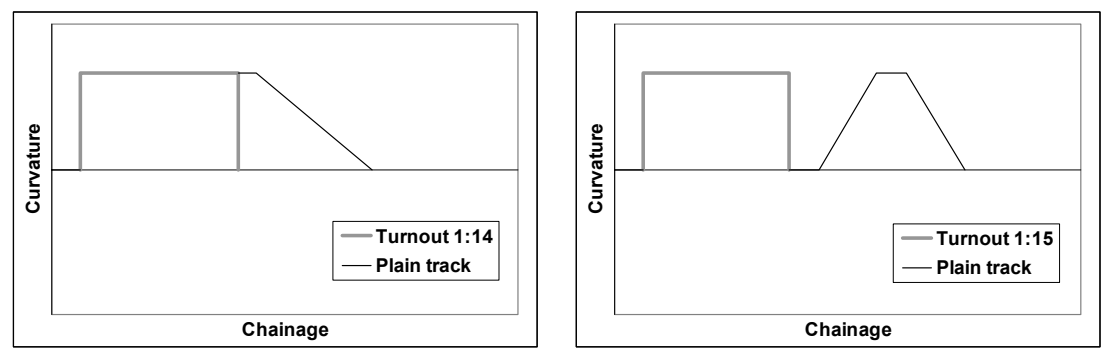

Figure 2: $\quad$ Curvature where the diverging track deviates from the main track with a larger angle than the turnout angle. A suitable layout with 1:14 turnout (left) and an unsuitable layout with a 1:15 turnout (right).
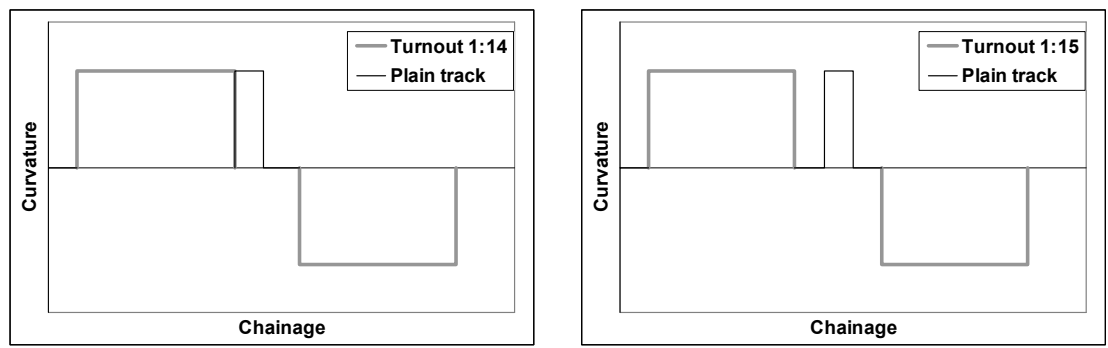

Figure 3: Curvature for a crossover between non-parallel main tracks. A suitable layout with 1:14 turnouts (left) and an unsuitable layout with 1:15 turnouts (right).

There are several variants of the cases illustrated in Figure 2. There are cases without enough space for transition curves, or the transition curves may be of substandard length. The horizontal curve in the plain track may be replaced by a second turnout. For Figure 3 (left), the second turnout may be a 1:15 turnout. The relevant aspect is that the first turnout has a continuous curve, directly connected with the horizontal curve in the plain track.

A turnout 1:15 followed by a curve in the same direction as the turnout curve may generate unfavourable vehicle motions. In Figures 4-6, lateral acceleration $\left[\mathrm{m} / \mathrm{s}^{2}\right]$, lateral jerk $\left[\mathrm{m} / \mathrm{s}^{3}\right]$ in the vehicle body (three positions), and lateral guiding forces $[\mathrm{kN}]$ (two outer wheels of the first bogie) are plotted against chainage. Dynamic vehicle response on alignments according to UIC60 1:14 is shown at the left, and according to UIC60 1:15 at the right. 


\section{Discussion and conclusions}

When wheelsets run on a circular curve under steady-state conditions, they will move laterally (in relation to track centre line) and take an angle of attack (angle between the wheel direction and the direction of the rail). The displacements depend on factors such as curve radius, suspension between wheelset and bogie
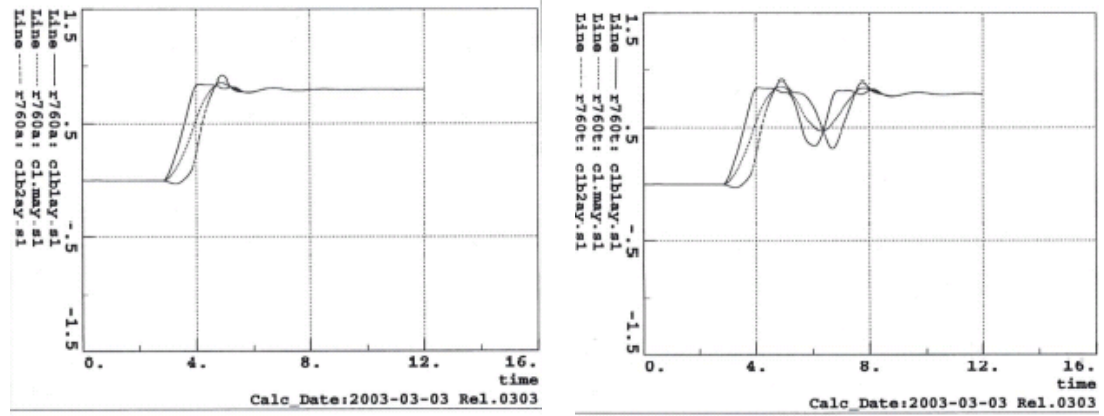

Figure 4: Lateral acceleration $\left[\mathrm{m} / \mathrm{s}^{2}\right]$ at three positions (above the bogies and in the middle of the coach) for a Eurofima coach passing a 1:14 turnout (left) and a 1:15 turnout (right), after the last bearer followed by a curve with $R=760 \mathrm{~m}$ in the same direction. Vehicle speed is $80 \mathrm{~km} / \mathrm{h}$.
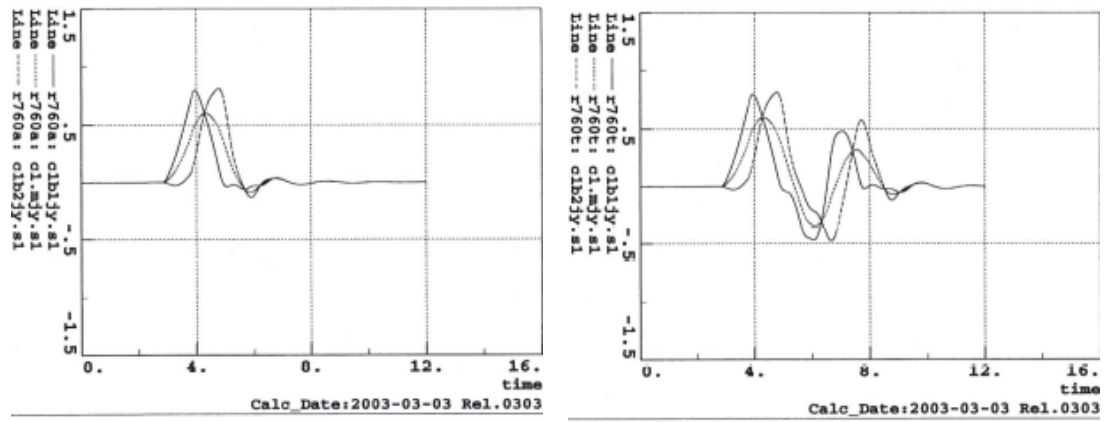

Figure 5: Lateral jerk $\left[\mathrm{m} / \mathrm{s}^{3}\right]$ at three positions (above the bogies and in the middle of the coach) for a Eurofima coach passing a 1:14 turnout (left) and a 1:15 turnout (right), after the last bearer followed by a curve with $R=760 \mathrm{~m}$ in the same direction. Vehicle speed is $80 \mathrm{~km} / \mathrm{h}$.

frame, wheel and rail profiles, friction conditions etc. However, on entering the curve, there will be a transient change from the lateral and yaw steady-state positions on the straight to new steady-state positions on the curve.

The simulations show that this transient change in positions increases the dynamic lateral wheel/rail forces at the wheel/rail interface compared to the 
steady-state values on the circular curve. For each curve entry, there is an unfavourable peak load. Such peak loads may be reduced by using transition curves. Hence, transition curves should preferably be used also on sidings, even though track standards may permit that horizontal curves are not provided with transitions under certain circumstances.

On circular curves in opposite directions with a short intermediate straight, the vehicle motions may be more transient on entering the second curve. This
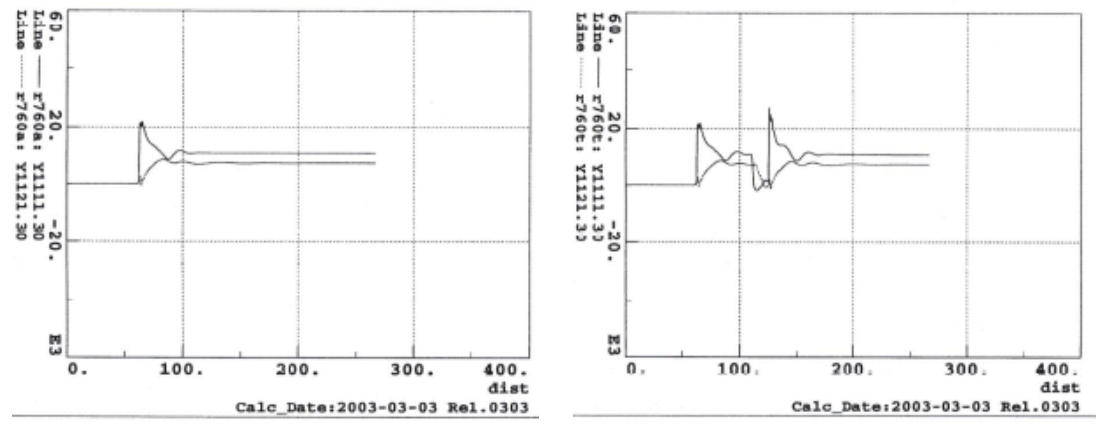

Figure 6: $\quad$ Guiding forces $Y[\mathrm{kN}]$ for the two wheel sets of the leading bogie of a Eurofima coach passing a 1:14 turnout (left) and a 1:15 turnout (right), after the last bearer followed by a curve with $R=760 \mathrm{~m}$ in the same direction. Vehicle speed is $80 \mathrm{~km} / \mathrm{h}$.

may justify modified turnouts with a straight at the heel. Tables 2 and 3 show that geometries according to 1:14 and 1:26.5 turnouts gives slightly worse vehicle response than 1:15 and 1:27.5 turnouts, when used in crossovers between tracks with $4.5 \mathrm{~m}$ track distance. However, compared to dynamic vehicle response on the alignments in Tables 4-5 (which are permitted according to Swedish track standards), the response on 1:14 and 1:26.5 is better. Hence, the question arises: Are the modified turnouts $1: 15$ and $1: 27.5$ really necessary?

Also circular curves in the same direction may generate transient vehicle motions if they are connected with a short intermediate straight. Therefore, modified turnouts with a straight at the heel, such as the $1: 15$ and 1:27.5, should be avoided where there is need for a connecting curve in the same direction.

According to the concept of virtual transitions, the lateral jerk should increase linearly with train speed in Table 4. Analysis [12] of early German literature [20] indicates that the concept of virtual transitions is based on incorrect assumptions, and the dynamic response in Tables $2-5$ does not support the assumed vehicle response according to virtual transitions.

The variables describing the motions of the vehicle body (lateral acceleration, lateral jerk and roll velocity) have been low-pass filtered according to the CEN standard for comfort evaluation [14], but also with two other types of filters. The magnitudes of the peak values vary with the filter used, but the conclusions when different alignment alternatives are compared remain the same. The same type of 
effect was observed when the type of vehicle was changed. The magnitudes of the variables changed, but the pattern remained the same.

\section{Acknowledgements}

The present study has been conducted in cooperation with professor Evert Andersson and professor Mats Berg at the Royal Institute of Technology, KTH, Stockholm. The computer models of the Eurofima coach and tilting train X2000 have been provided by Desolver AB and Bombardier Transportation, respectively.

\section{References}

[1] Hashimoto, S. Analysis of relationship between transition curve profile and railway vehicle vibration. Quarterly Report of RTRI 1989, vol. 30(4) pp 207-214.

[2] Kufver, B. Realigning railways in track renewals - Linear versus S-shaped superelevation ramps. Proc. of Railway Engineering -99, ECS Publications: Edinburgh. ISBN 0-947644-39-3.

[3] Kufver, B. Dynamic vehicle reactions on the Ruch type of S-shaped superelevation ramps. Proc. of Comprail 2000, CMP/WIT Press: Southampton, pp. 663-672. ISBN 1-85312-598-9.

[4] Klauder, L.T. \& Chrismer, S.M. Improving spiral geometry of existing tracks. Proc. of Railway Engineering - 2003, Engineering Technics Press: Edinburgh. ISBN 0-947644-51-2.

[5] Miyagaki, K., Adachi, M. \& Sato, Y. Analytical study on effects of form in transition curve. Paper presented at the IAVSD conference in Japan 2003.

[6] Liu, Z. Rail/wheel dynamics simulation for transition curve in the high speed test section of Qinshen passenger railway line. Proc. of Railway Engineering - 2004. Engineering Technics Press: Edinburgh. ISBN 0947644-55-5.

[7] Kufver, B. Dynamic vehicle response on short circular curves and tangent tracks. Proc. of Railway Engineering - 2003, Engineering Technics Press: Edinburgh. ISBN 0-947644-51-2.

[8] Kufver, B. \& Andersson, E. Optimisation of lengths of transition curves with vehicle reactions taken into consideration. Proc. of Comprail 98, CMP/WIT Press: Southampton, pp. 33-42. ISBN 1-85312-598-9.

[9] Kufver, B. Optimisation of clothoid lengths - simulations dynamic vehicle reactions on horizontal curves with track irregularities. Proc. of Railway Engineering - 2000. Engineering Technics Press: Edinburgh. ISBN 0947644-43-1.

[10] Kufver, B. \& Rydell, O. Standardväxel UIC60 1:14 eller specialväxel UIC60 1:15 (Standard turnout UIC60 1:14 versus special turnout UIC60 1:15, published in Swedish only). Paper presented at the 11th Nordic Seminar on Railway Technology, 31 March - 1 April 2003, Copenhagen, Denmark. 
[11] Kufver, B. \& Rydell, O. Dynamic vehicle response on horizontal curves without transition curves, including turnout curves through Swedish UIC60 turnouts. VTI:s fack- och monterseminarier vid Nordic Rail 2003, VTI Konferens 20. VTI: Linköping.

[12] Kufver, B. \& Förstberg, J. Dynamic vehicle response versus virtual transitions. Proc. of Comprail 2004, CMP/WIT Press: Southampton, pp 799-807. ISBN 1-85312-715-9.

[13] Kufver, B. Optimisation of horizontal alignments for railways - Procedures involving evaluation of dynamic vehicle response. $\mathrm{PhD}$ thesis, TRITA-FKT Report 2000:47, KTH: Stockholm.

[14] CEN. Railway applications - Ride comfort for passengers - Measurement and evaluation. ENV 12299:1999, European Committee for Standardization, Brussels.

[15] CEN. Railway applications - Testing for the acceptance of running characteristics of railway vehicles - Testing of running behaviour and stationary tests. EN 14363:2005, European Committee for Standardization, Brussels.

[16] UIC. Testing and approval of railway vehicles from the point of view of their dynamic behaviour - Safety - Track fatigue - Ride quality, UIC code $518,2^{\text {nd }}$ ed. (April 2003). Paris: International Union of Railways, Paris.

[17] $\mathrm{BV}$. Tillåten hastighet mht spårets geometriska form. (Permissible speed with respect to track geometry, published in Swedish only). BVF 586.41, Banverket, Borlänge. 1996.

[18] CEN. Railway applications - Track - Track alignment design parameters Track gauges $1435 \mathrm{~mm}$ and wider - Part 2: Switches and crossings and comparable alignment design situations with abrupt changes of curvature. EN 13803-2:2006, European Committee for Standardization, Brussels.

[19] Kufver, B. \& Rydell, O. Certain aspects on the CEN standard for alignments through switches and crossings. Proc. of Railway Engineering 2007. Engineering Technics Press: Edinburgh. ISBN 0-947644-61-10.

[20] Vogel, R. Bewertung der Gleisverbindungen S 49 nach dem "Ruck”. Organ für die Fortschritte des Eisenbahnwesens in technischer Beziehung. 91(20), pp. 413-419. 1936. 